\title{
Genome Structure of Intro-Gressive Lines Triticum Aes-Tivum/Aegilops Sharonensis
}

\author{
M. Z. Antonyuk, M. V. Bodylyova, and T. K. Ternovskaya \\ The National University "Kyiv-Mohyla Academy”, Ukraine
}

\begin{abstract}
The lines Triticum aestivum/Aegifops sharonensis were explored in regard to the presence of introgressions in the line genomes, their amount and belonging to definite homoeologic group. The results of studying of chromosome associations in M1 of PMC in the hybrids between the lines with each other and with recurrent common wheat genotype Avrora were compared with the data of the line assessmentfor the chromosomal biochemical and morphological markers. 26 lines were distinguished, between six groups with specific genome rearrangement regard to recurrent genotype.
\end{abstract}

\section{INTRODUCTION}

In recent years, introgressive plant material, including wheat plant material, is actively used for development of mapping populations [1-5]. Using the mapping population for gene linkage determination, the comparison between the empirical ant theoretical rations of phenotype classes is carried out. When calculating the theoretical class volume we need to be sure that meiosis in the $F_{1}$ plants proceeds without abnormalities, otherwise, we can obtain the artefacts. The causes of artefact appearance were analyzed in our review [6].

The group of introgressive lines Triticum aestivum/Aegilops sharonensis with certain alien characters was investigated. These lines are applicable to be used in genetic analysis of wheat for the genes that control alien gradation of characters. Detailed cytogenetic examination of introgressive lines concerning their cytological stability is the first and necessary step when using such lines for development of mapping population. Moreover, the cytogenetical peculiarities of the $\mathrm{F}_{1}$ hybrids from crosses of the lines with each other, which are the direct source of the mapping population, should be studied as well.

\section{MATERIALS AND METHODS}

(1) 26 hexaploid introgressive lines of common wheat with alien genetic material from Ae. sharonensis. The lines were developed by Ternovskaya [7] by the method of chromosome mixing that was proposed and theoretically proved by Zhirov [8]. These lines were obtained by crossing between genome substitution form Avrosis (AABBS ${ }^{1} \mathrm{~S}^{1}$ ) and winter common wheat variety Avrora (AABBDD), which was a source of tetraploid component AABB in genome of Avrosis [8].
The variety Avrora was recurrent genotype in following crosses of hybrid AABBDS ${ }^{1}$ in the course of line development. (2) Hybrids $F_{1}$ from crosses of the lines with each other and the variety Avrora. (3) The Avrora variety, the Avrosis form. Plants were grown in field.

All plant material was studied as to spike morphology characters, their description is given in Table 1 . Protein electrophoretic spectra of glutenins, gliadins [9], alpha- and beta-amylase [10], seed and leaf peroxidase [11], seed and leaf esterase [12], acid phosphatase [13] were obtained and analyzed for all strains. The electrophoresis techniques were published in relevant references. Genomic DNA was extracted from young leaf tissue as previously described in [14]. Wheat microsatellite primer pairs were developed and mapped on 4D chromosome by [15]. PCR conditions were as described by [16].

Meiosis was studied in the first meiotic metaphase (M1) and in tetrads of pollen mother cells (PMC). Spike located between the second and the third leaves was taken out and its anthers were isolated and fixed in $2 \%$ acetocarmine. Fixed material was stored at $4^{\circ} \mathrm{C}$. Information about chromosome associations in meiotic M1 and the number of micronuclei in tetrad cells of the $\mathrm{F}_{1}$ hybrids between the Avrora variety and each of the line was used to determine the number of chromosome substitution and large translocation in the line genomes. The univalent number under the highest chromosome association divided by two indicate alien chromosome number in the hybrid genome, that is in the line genome, with which the hybrid was obtained [8]. When the data about meiotic M1 are absent, the univalent number could be determined indirect, using the micronuclei number in tetrads. Any univalent has the probability 0.75 to lag in anaphase and to form micronucleus, that is to say the micronuclei number in tetrads indi- 
Table 1. Description of the T. aestivum/Ae. sharonensis lines for the spike morphology characters

\begin{tabular}{|c|c|c|c|c|c|c|c|c|c|c|}
\hline Lines & Awnedness ${ }^{1)}$ & $\begin{array}{c}\text { Spike } \\
\text { shape and } \\
\text { density }^{2)}\end{array}$ & $\begin{array}{c}\text { Glaucous } \\
\text { ness }^{3)}\end{array}$ & $\begin{array}{c}\text { Color } \\
\text { of mature } \\
\text { spike }^{4)}\end{array}$ & $\begin{array}{c}\text { Glume } \\
\text { hairyness }^{5}\end{array}$ & $\begin{array}{l}\text { Glume } \\
\left.\text { shape }^{6}\right)\end{array}$ & $\begin{array}{c}\text { Pit } \\
\text { of glume } \\
\text { base }^{7)}\end{array}$ & $\begin{array}{c}\text { Tenacious } \\
\text { glume }\end{array}$ & $\begin{array}{l}\text { Anther } \\
\left.\text { color }^{9}\right)\end{array}$ & $\begin{array}{l}\text { Hairy leaf } \\
\text { sheath }^{10)}\end{array}$ \\
\hline res 118 & 2 & 3 & 2 & 1 & 1 & 1 & 1 & 1 & 1 & 2 \\
\hline res 121 & 2 & 3 & 2 & 1 & 3 & 1 & 3 & 1 & 1 & 1 \\
\hline res 122 & 2 & 3 & 2 & 1 & 3 & 2 & 1 & 2 & 1 & 1 \\
\hline res 146 & 2 & 3 & 2 & 1 & 3 & 2 & 1 & 1 & 1 & 1 \\
\hline res 115 & 2 & 1 & 1 & 1 & 2 & 1 & 1 & 1 & 1 & 2 \\
\hline res 117 & 2 & 1 & 2 & 1 & 1 & 1 & 1 & 2 & 1 & 2 \\
\hline res 128 & 2 & 1 & 1 & 1 & 2 & 1 & 1 & 2 & 1 & 2 \\
\hline res 131 & 2 & 1 & 1 & 1 & 3 & 1 & 1 & 2 & 2 & 2 \\
\hline res 132 & 2 & 1 & 2 & 1 & 3 & 1 & 2 & 2 & 1 & 1 \\
\hline res 137 , res 139 & 2 & 1 & 2 & 1 & 2 & 1 & 1 & 2 & 1 & 2 \\
\hline res 138 , res 140 & 2 & 1 & 1 & 1 & 2 & 1 & 1 & 1 & 1 & 2 \\
\hline res 145 & 2 & 1 & 1 & 1 & 3 & 2 & 3 & 2 & 1 & 1 \\
\hline res 148 & 2 & 1 & 2 & 1 & 1 & 1 & 3 & 2 & 1 & 1 \\
\hline res 126 & 3 & 2 & 1 & 1 & 1 & 1 & 1 & 2 & 2 & 1 \\
\hline res 129, res 130 & 3 & 1 & 1 & 1 & 1 & 1 & 1 & 1 & 2 & 1 \\
\hline res 134 & 3 & 1 & 1 & 1 & 2 & 1 & 1 & 2 & 1 & 2 \\
\hline res 143 & 3 & 1 & 1 & 1 & 1 & 1 & 1 & 1 & 1 & 1 \\
\hline res 127 & 1 & 1 & 1 & 1 & 1 & 1 & 2 & 3 & 1 & 2 \\
\hline res 135 & 1 & 1 & 1 & 2 & 1 & 1 & 3 & 3 & 1 & 2 \\
\hline res 136 & 1 & 1 & 1 & 1 & 1 & 1 & 2 & 2 & 2 & 2 \\
\hline res 141 , res 142 & 1 & 1 & 1 & 1 & 1 & 1 & 1 & 1 & 2 & 1 \\
\hline res 144 & 1 & 1 & 1 & 1 & 1 & 1 & 2 & 3 & 2 & 1 \\
\hline
\end{tabular}

Note: Such the character gradation are numerated in appropriate columns: ${ }^{1)} 1$ - awnedless, 2 -awned, 3 -awn-like sprouts; ${ }^{2)} 1$ - spindleshaped, 2 - speltoid, 3 - lax; ${ }^{3)} 1$ - glaucous glume, 2 -nonglaucous glume; ${ }^{4)} 1$ - white, 2 - brown; ${ }^{5)} 1$ - without hairy, 2 - homogeneous hairy, 3 - nonhomogeneous hairy; ${ }^{6)} 1$ - oval, 2 - elongated; ${ }^{7)} 1$ - is present, 2 - is absent, 3 - is weak expressed; ${ }^{8)} 1$ soft, 2 - tenacious, 3 - very tenacious; ${ }^{9)} 1$ - yellow, 2 - reddish-violet.; ${ }^{10)} 1$ - leaf sheath without hairiness, 2 - hairy leaf sheath. Variety Avrora has been marked by gradation 1 for the all characters.

cates a number of unpaired chromosome in meiotic M1, so the alien chromosome number.

Calculation of averages with errors and their comparison were carried out with the use of standard methods of biological statistics [17].

\section{RESULTS AND DISCUSSION}

Introgressive lines which phenotype is differed from phenotype of variety Avrora concerning one of the characters of spike morphology were selected for genome structure examination (Table 1). Just these distinctions were considered by us as a proof of presence of the genetic material from Ae. sharonensis in the line genome.

It is known that the character glaucous/nonglaucous glume is a morphological marker of chromosome 2D [18]. The lax spike is inherent in the wheat plant with the substitutions for the chromosomes of the $6^{\text {th }}$ homoeologic group $[19,20]$. Genes controlling tenacious glume and pit at its base are localized on chromosome 2D [21, 22]. Anthocyan pigmentation gene, which is easily observed in case of reddish-violet coloration of anthers, is located on chromosomes of the 7th homoeology group [18]. Therefore, data in Table 1 not only indicate alien chromatin presence in the genomes of studied lines, but also assign certain information about homoeologic belonging of this chromatin.

Electrophoretic spectra of storage proteins (the 1st cbromosome) [9], beta-amylase [10] and acid phosphatase (the 4th chromosome) [13], seed esterase (the $3 \mathrm{~d}$ chromosome) [12], leaf esterase (the 7th chromosome) [12], leaf peroxidase (the 7th chromosome) [11] were found to be the biochemical markers of introgressions in the genome of wheat variety Avrora originated from the species Ae. sharonensis. Screening of the studied lines for the mentioned proteins showed the absence of the diagnostic changes in the spectra of storage proteins, alpha-amylase, seed and leaf peroxidase. So, the lines could not be considered as carriers of whole alien chromosome of appropriate homoeol-ogous group. At 
the same time, data of Table 2 indicate that none of the studied lines is characterized by electrophoretic spectra similar to corresponding electrophoretic spectra of variety Avrora. Electrophoretic spectra of beta-amylase, acid phosphatase, seed and leaf esterase in some studied lines differ from electrophoretic spectra of variety Avrora. The marker components controlled by genes $\beta$-Amy-S1 and Acph-S1, located on long arm of chromosome $4 S^{1}$, are inhered in 12 introgressive lines. Translocation with breakpoint between these genes is not detected: all lines are characterized by two alien components that are controlled by $\beta-A m y-S 1$ and Acph-S1, or two wheat components. Marker components Est-S1, controlled by chromosome $3 \mathrm{~S}^{1}$, were found on spectra of nine lines. Components of electrophoretical spectra controlled by gene Est-2, localized on the long arm of chromosome 3D, were absent on leaf esterase spectra in five lines; components, controlled by gene Est-1, which is localized on chromosome arm 3DS, are absent in 12 lines. These results can be considered as indirect argument of substitution of certain wheat chromosome segments for the alien ones.

It is seen from the Table 3 that all studied lines are characterized by greater number of closed biva-lents in M1 in comparison with variety Avrora. That is to say, Avrora has some number of univalents and open bivalents in M1. This fact should be explained by the presence of the spontaneous translocation 1BL.1RS in the Avrora genome [23] and by the effect of partial desynapsis genes located on chromosomes $2 \mathrm{~B}$ and $3 \mathrm{~B}$ [24]. This should be taken into consideration when analyzing the patterns of chromosome association in M1 of the $\mathrm{F}_{1}$ hybrids between introgressive lines with each other and the variety Avrora. So, not only the presence of introgressions in genomes of the cross components, but also peculiarity of the variety Avrora genome can decrease pairing between chromosomes. Consequently, the presence of rod (open) bivalents remains to be insufficient for indication of variation in line genome structure in comparison with variety Avrora genome. It is possible that the negative influence of wheat desynapsis genes can be compensated by the presence of alien chromatin.

In the $\mathrm{F}_{1}$ hybrid between the chromosome substitution line and variety Avrord the chromosomes of the D and $\mathrm{S}$ genomes out of the same homoeol-ogous group can not pair with each other and keep as univalents. Chromosomes of the A and B genomes should be paired without irregularities, although marginal probability of association between the S-chromosomes and the chromosomes from the A, B, and D genomes may be left. The triploid hybrid tetra-Avrora $\times$ Ae. sharonensis $\left(\mathrm{ABS}^{1}\right)$ was shown to form 0.06 trivalents per cell [25]. Moreover, it is impossible to exclude the possibility of D-S associations with forming of hetero-morphic bivalents. Although, pairing between wheat and alien (Ae. sharonensis) chromosomes is extremely reduced, it occurs with minor frequency [26, 27]. So, a number of bivalents and univalents under highest chromosome
Table 2. Assessment of the T. aestivum/Ae. sharonensis lines for presence of electrophoretic spectrum bands that are diagnostic for some biochemical genes concerning chromosomes of the D and $S^{1}$ genomes

\begin{tabular}{c|c|c|c|c|c}
\hline Line & $\beta-$ Amy-l & Acph-1 & Est- & Est-2 & Est-3 \\
\hline res 115 & $4 \mathrm{~S}^{1}$ & $4 \mathrm{~S}^{1}$ & - & - & $7 \mathrm{D}$ \\
res 117 & $4 \mathrm{~S}^{1}$ & $4 \mathrm{~S}^{1}$ & $3 \mathrm{~S}^{1}$ & - & $7 \mathrm{D}$ \\
res 118 & $4 \mathrm{~S}^{1}$ & $4 \mathrm{~S}^{1}$ & $3 \mathrm{~S}^{1}$ & $3 \mathrm{D}$ & $7 \mathrm{D}$ \\
res 121 & $4 \mathrm{D}$ & $4 \mathrm{D}$ & & $3 \mathrm{D}$ & $7 \mathrm{D}$ \\
res 122 & $4 \mathrm{D}$ & $4 \mathrm{D}$ & & $3 \mathrm{D}$ & $7 \mathrm{D}$ \\
res 126 & $4 \mathrm{~S}^{1}$ & $4 \mathrm{~S}^{1}$ & & $3 \mathrm{D}$ & $7 \mathrm{D}$ \\
res 127 & $4 \mathrm{D}$ & $4 \mathrm{D}$ & $3 \mathrm{D}$ & $3 \mathrm{D}$ & $7 \mathrm{~S}^{1}$ \\
res 128 & $4 \mathrm{~S}^{1}$ & $4 \mathrm{~S}^{1}$ & $3 \mathrm{~S}^{1}$ & $3 \mathrm{D}$ & $7 \mathrm{D}$ \\
res 129 & $4 \mathrm{D}$ & $4 \mathrm{D}$ & $3 \mathrm{~S}^{1}$ & $3 \mathrm{D}$ & $7 \mathrm{D}$ \\
res 130 & $4 \mathrm{D}$ & $4 \mathrm{D}$ & $3 \mathrm{~S}^{1}$ & $3 \mathrm{D}$ & $7 \mathrm{D}$ \\
res 131 & $4 \mathrm{~S}^{1}$ & $4 \mathrm{~S}^{1}$ & $3 \mathrm{~S}^{1}$ & - & $7 \mathrm{D}$ \\
res 132 & $4 \mathrm{D}$ & $4 \mathrm{D}$ & - & $3 \mathrm{D}$ & $7 \mathrm{D}$ \\
res 134 & $4 \mathrm{~S}^{1}$ & $4 \mathrm{~S}^{1}$ & - & $3 \mathrm{D}$ & $7 \mathrm{D}$ \\
res 135 & $4 \mathrm{~S}^{1}$ & $4 \mathrm{~S}^{1}$ & - & $3 \mathrm{D}$ & $7 \mathrm{D}$ \\
res 136 & $4 \mathrm{~S}^{1}$ & $4 \mathrm{~S}^{1}$ & $3 \mathrm{~S}^{1}$ & $3 \mathrm{D}$ & $7 \mathrm{~S}^{1}$ \\
res 137 & $4 \mathrm{~S}^{1}$ & $4 \mathrm{~S}^{1}$ & - & - & $7 \mathrm{D}$ \\
res 138 & $4 \mathrm{~S}^{1}$ & $4 \mathrm{~S}^{1}$ & - & $3 \mathrm{D}$ & $7 \mathrm{D}$ \\
res 139 & $4 \mathrm{~S}^{1}$ & $4 \mathrm{~S}^{1}$ & $3 \mathrm{~S}^{1}$ & - & $7 \mathrm{D}$ \\
res 140 & $4 \mathrm{~S}^{1}$ & $4 \mathrm{~S}^{1}$ & - & - & $7 \mathrm{D}$ \\
res 141 & $4 \mathrm{D}$ & $4 \mathrm{D}$ & $3 \mathrm{~S}^{1}$ & $3 \mathrm{D}$ & $7 \mathrm{~S}^{1}$ \\
res 142 & $4 \mathrm{D}$ & $4 \mathrm{D}$ & $3 \mathrm{D}$ & $3 \mathrm{D}$ & $7 \mathrm{~S}^{1}$ \\
res 143 & $4 \mathrm{D}$ & $4 \mathrm{D}$ & $3 \mathrm{~S}^{1}$ & $3 \mathrm{D}$ & $7 \mathrm{D}$ \\
res 144 & $4 \mathrm{D}$ & $4 \mathrm{D}$ & $3 \mathrm{D}$ & $3 \mathrm{D}$ & $7 \mathrm{~S}^{1}$ \\
res 145 & $4 \mathrm{D}$ & $4 \mathrm{D}$ & $3 \mathrm{D}$ & $3 \mathrm{D}$ & $7 \mathrm{~S}^{1}$ \\
res 146 & $4 \mathrm{D}$ & $4 \mathrm{D}$ & - & - & $7 \mathrm{D}$ \\
res 148 & $4 \mathrm{D}$ & $4 \mathrm{D}$ & - & $3 \mathrm{D}$ & $7 \mathrm{D}$ \\
\hline
\end{tabular}

association in meiosis M1 of hybrid between the introgressive line and variety Avrora (Tables 5 and 4) and knowledge about homoeologous belonging of introgressions (Tables 1 and 2) remain to be the main sources of information about line genome structure. The number of univalents divided at two points on amount of substituted chromosomes in line, and number of open bivalents indicate the presence of translocations in line genome. These translocations can an include alien genetic material, but they, also, can be extremely wheat-wheat. Some hybrids between introgressive lines and cultivar Avrora are characterized by greater number of closed bivalents, than in variety Avrora. It does not contradict the data about recessiveness of desynapsis genes, which presence was shown for variety Aurora [24].

It is clear, that line genomes are considerably changed in comparison with genome of variety Avrora 
Table 3. Averages with errors for the bivalent and univalent numbers in Ml of PMC of the studied fines and variety Avrora

\begin{tabular}{|c|c|c|c|c|}
\hline Line & Cell number & $\begin{array}{l}\text { Ring } \\
\text { bivalents }\end{array}$ & Rod bivalents & Univalents \\
\hline Avrora & 48 & $16.76 \pm 0.191 *$ & $4.14 \pm 0.191 *$ & $0.33 \pm 0.11$ \\
\hline res 115 & 102 & $18.53 \pm 0.13$ & $1.96 \pm 0.11$ & $0.90 \pm 0.11$ \\
\hline res 117 & 109 & $19.26 \pm 0.09$ & $1.29 \pm 0.07$ & $0.90 \pm 0.10$ \\
\hline res 118 & 74 & $19.00 \pm 0.12$ & $1.68 \pm 0.10$ & $0.59 \pm 0.11 * *$ \\
\hline res 121 & 102 & $18.57 \pm 0.13$ & $2.06 \pm 0.13$ & $0.61 \pm 0.09$ \\
\hline res 122 & 47 & $18.40 \pm 0.14$ & $2.17 \pm 0.16$ & $0.85 \pm 0.15$ \\
\hline res 126 & 77 & $19.82 \pm 0.07$ & $0.84 \pm 0.04$ & $1.01 \pm 0.11$ \\
\hline res 127 & 78 & $17.96 \pm 0.12$ & $2.51 \pm 0.13$ & $1.05 \pm 0.11$ \\
\hline res 128 & 87 & $18.62 \pm 0.10$ & $1.92 \pm 0.12$ & $0.69 \pm 0.10$ \\
\hline res 129 & 102 & $18.77 \pm 0.10$ & $2.06 \pm 0.10$ & $0.43 \pm 0.08 * *$ \\
\hline res 130 & 85 & $18.91 \pm 0.09$ & $1.74 \pm 0.08$ & $0.68 \pm 0.10$ \\
\hline res 131 & 72 & $18.96 \pm 0.17$ & $1.75 \pm 0.15$ & $0.44 \pm 0.10 * *$ \\
\hline res 132 & 80 & $18.30 \pm 0.11$ & $2.20 \pm 0.14$ & $1.00 \pm 0.11$ \\
\hline res 134 & 76 & $18.61 \pm 0.19$ & $2.07 \pm 0.16$ & $0.58 \pm 0.10 * *$ \\
\hline res 135 & 34 & $19.26 \pm 0.11$ & $1.56 \pm 0.09$ & $0.35 \pm 0.13^{* *}$ \\
\hline res 136 & 132 & $19.04 \pm 0.12$ & $1.67 \pm 0.10$ & $0.48 \pm 0.07 * *$ \\
\hline res 137 & 69 & $18.01 \pm 0.26$ & $2.55 \pm 0.21$ & $0.81 \pm 0.11$ \\
\hline res 138 & 93 & $19.85 \pm 0.06$ & $1.01 \pm 0.05$ & $0.56 \pm 0.09 * *$ \\
\hline res 139 & 82 & $18.98 \pm 0.15$ & $1.75 \pm 0.13$ & $0.43 \pm 0.09 * *$ \\
\hline res 140 & 52 & $19.40 \pm 0.12$ & $1.40 \pm 0.12$ & $0.81 \pm 0.14$ \\
\hline res 141 & 69 & $18.55 \pm 0.13$ & $2.29 \pm 0.13$ & $0.46 \pm 0.10 * *$ \\
\hline res 142 & 61 & $19.13 \pm 0.14$ & $1.67 \pm 0.12$ & $0.30 \pm 0.12 * *$ \\
\hline res 143 & 96 & $18.56 \pm 0.17$ & $2.06 \pm 0.14$ & $0.73 \pm 0.10$ \\
\hline res 144 & 75 & $18.27 \pm 0.12$ & $2.20 \pm 1.15$ & $1.07 \pm 0.12$ \\
\hline res 145 & 106 & $18.29 \pm 0.10$ & $2.17 \pm 0.13$ & $1.08 \pm 0.10$ \\
\hline res 146 & 120 & $18.38 \pm 0.09$ & $2.03 \pm 0.11$ & $1.17 \pm 0.10$ \\
\hline res 148 & 97 & $18.36 \pm 0.10$ & $2.07 \pm 0.12$ & $1.13 \pm 0.10$ \\
\hline
\end{tabular}

Notes: $* \mathrm{t}_{\mathrm{emp}}>\mathrm{t}_{\mathrm{st} 0.01}$ for the all lines at comparison with the variety Avrora as to the number of ring and open bivalents (the Bonferroni $t$ test was used because of multiple comparison procedure), $* * \mathrm{t}_{\mathrm{emp}}<\mathrm{t}_{\mathrm{st} 0.05}$ at comparison of the line with the variety Avrora as to the univalent number.

(Table 4). They include wheat-alien chromosome substitutions and large translocations concerning from 1 to 4 chromosome pairs in each line. Line res 126 is characterized by one pair of substituted chromosomes. Lines res 121, res 122 , res 130 , res 132 , res 144 , res 145 , res 146 , and res 148 carry one pair of substituted chromosomes and one translocation, lines res 134, res 142 , and res 143 include one pair of substituted chromosomes and two translocations, lines res 115 , res 117 , res 127 , res 129 , res 135 , and res 141 carry two pairs of substituted chromosomes, lines res 118 , res 128 , res 138 , and res 140 have two pairs of substituted chromosomes and one translocation. Evidently, lines res 136, res 137, res 139 possess two pairs of substituted chromosomes and two translocations.

Genome structure of the lines can be detailed using as a base the meiosis $\mathrm{Ml}$ pattern in hybrids $\mathrm{F}_{1}$ between lines with each other (Table 5). These results demonstrate what kind of introgression characterizes the line, chromosome substitution or translocation. In addition to cytological characterization, the line were analyzed with the use of biochemical markers that are specific for definite homoeologous chromosome group of Triticinae. The lines with similar genome structure form 21 closed bivalent. These lines are res 121 and res 148, res 122 and res 148 , res 122 and res 130, res 126 and res 144, res 132 and res 121 , res 144 and res 145 , res 148 and res 146, also, res 137 and res 118, res 137 and res 138, res 138 and res 117 . If four univalents occur in metaphase 1 of meiosis in the $F_{1}$ hybrid between lines, each out of the lines has an alien chromosome substitution, but the lines differ from each other concerning homoeologic belonging of the alien chromosomes. Results represented in Tables 1 , 2,4 , and 5 allow us to characterize each line regarding the alien chromosome presence, their homoeologic belonging, and translocation presence (Table 6). 
Table 4. Chromosome configuration under the highest chromosome association in $\mathrm{M} 1$ of PMC in hybrids $\mathrm{F}_{1}$ at crossing the studied lines with variety Avrora

\begin{tabular}{|c|c|c|c|c|c|}
\hline $\begin{array}{l}\text { Line crossed } \\
\text { with Avrora }\end{array}$ & Number of cell & $\begin{array}{l}\text { Chromosome configu- } \\
\text { ration in meiotic M1* }\end{array}$ & $\begin{array}{l}\text { Line crossed } \\
\text { with Avrora }\end{array}$ & Number of cell & $\begin{array}{l}\text { Chromosome configu- } \\
\text { ration in meiotic M1* }\end{array}$ \\
\hline res 115 & 74 & $19^{\mathrm{IIc}}+4^{\mathrm{I}}$ & res 135 & 64 & $19^{\mathrm{IIc}}+4^{\mathrm{I}}$ \\
\hline res 117 & 96 & $19^{\mathrm{IIc}}+4^{\mathrm{I}}$ & res 136 & 72 & $17^{\mathrm{IIc}}+2^{\mathrm{IIo}}+4^{\mathrm{I}}$ \\
\hline res 118 & 64 & $18^{\mathrm{IIc}}+1^{\mathrm{IIo}}+4^{\mathrm{I}}$ & res 137 & 73 & $17^{\mathrm{IIc}}+2^{\mathrm{IIo}}+4^{\mathrm{I}}$ \\
\hline res 121 & 32 & $19^{\mathrm{IIc}}+1^{\mathrm{IIo}}+2^{\mathrm{I}}$ & res 138 & 60 & $18^{\mathrm{IIc}}+1^{\mathrm{IIo}}+4^{\mathrm{I}}$ \\
\hline res 122 & 87 & $19^{\mathrm{IIc}}+1^{\mathrm{IIo}}+2^{\mathrm{I}}$ & res 139 & 112 & $17^{\mathrm{IIc}}+2^{\mathrm{IIo}}+4^{\mathrm{I}}$ \\
\hline res 126 & 71 & $19^{\mathrm{IIc}}+2^{\mathrm{I}}$ & res 140 & 39 & $18^{\mathrm{IIc}}+1^{\mathrm{IIo}}+2^{4}$ \\
\hline res 127 & 88 & $19^{\mathrm{IIc}}+4^{\mathrm{I}}$ & res 141 & 63 & $19^{\mathrm{II} c}+4$ \\
\hline res 128 & 56 & $18^{\mathrm{IIc}}+1^{\mathrm{IIo}}+4^{\mathrm{I}}$ & res 142 & 94 & $18^{\mathrm{IIc}}+2^{\mathrm{IIo}}+2^{\mathrm{I}}$ \\
\hline res 129 & 48 & $19^{\mathrm{IIc}}+4^{\mathrm{I}}$ & res 143 & 102 & $18^{\mathrm{IIc}}+2^{\mathrm{IIo}}+2^{\mathrm{I}}$ \\
\hline res 130 & 93 & $19^{\mathrm{IIc}}+1^{\mathrm{IIo}}+2^{\mathrm{I}}$ & res 144 & 48 & $19^{\mathrm{IIc}}+1^{\mathrm{IIo}}+2^{\mathrm{I}}$ \\
\hline res 132 & 76 & $19^{\mathrm{IIc}}+1^{\mathrm{IIo}}+2^{\mathrm{I}}$ & res 145 & 39 & $19^{\mathrm{IIc}}+1^{\mathrm{IIo}}+2^{\mathrm{I}}$ \\
\hline res 134 & 81 & $18^{\mathrm{IIc}}+1^{\mathrm{IIo}}+2^{\mathrm{I}}$ & res 146 & 88 & $19^{\mathrm{IIc}}+1^{\mathrm{IIo}}+2^{\mathrm{I}}$ \\
\hline res 131 & 96 & $19^{\mathrm{II} c}+4^{\mathrm{I}}$ & res 148 & 79 & $19^{\mathrm{IIc}}+1^{\mathrm{IIo}}+2^{\mathrm{I}}$ \\
\hline
\end{tabular}

Note: * In Table 4 and 5: IIc - closed (ring) bivalent; ${ }^{\text {IIo }}$ - open (rod) bivalent; $I$ - univalent.

Table 5. Chromosome configuration under the highest chromosome association in $\mathrm{M} 1$ of $\mathrm{PMC}$ in hybrids $\mathrm{F}_{1}$ at crossing the studied lines with each other

\begin{tabular}{|c|c|c|c|c|c|}
\hline Cross & Number of cell & $\begin{array}{l}\text { Chromosome configu- } \\
\text { ration in meiotic M1 }\end{array}$ & Cross & Number of cell & $\begin{array}{l}\text { Chromosome configu- } \\
\text { ration in meiotic M1 }\end{array}$ \\
\hline $115 \times 117$ & 28 & $19^{\mathrm{IIc}}+2^{\mathrm{IIo}}$ & $135 \times 128$ & 42 & $18^{\mathrm{IIc}}+3^{\mathrm{IIo}}$ \\
\hline $115 \times 139$ & 37 & $18^{\mathrm{IIc}}+3^{\mathrm{IIo}}$ & $135 \times 139$ & 43 & $19^{\mathrm{IIc}}+2^{\mathrm{IIo}}$ \\
\hline $115 \times 148$ & 41 & $18^{\mathrm{IIc}}+1^{\mathrm{IIo}}+4^{\mathrm{I}}$ & $136 \times 129$ & 38 & $17^{\mathrm{IIc}}+2^{\mathrm{IIo}}+4^{\mathrm{I}}$ \\
\hline $117 \times 118$ & 18 & $19^{\mathrm{IIc}}+2^{\text {IIo }}$ & $136 \times 143$ & 29 & $16^{\mathrm{IIc}}+6^{\mathrm{I}^{*}}$ \\
\hline $117 \times 134$ & 24 & $20^{\mathrm{IIc}}+1^{\mathrm{IIo}}$ & $136 \times 134$ & 13 & $18^{\mathrm{IIc}}+2^{\mathrm{IIo}}+2^{\mathrm{I}^{*}}$ \\
\hline $121 \times 122$ & 61 & $20^{\mathrm{IIc}}+1^{\mathrm{IIo}}$ & $137 \times 117$ & 26 & $19^{\mathrm{IIc}}+2^{\mathrm{IIo}}$ \\
\hline $121 \times 128$ & 28 & $18^{\mathrm{IIc}}+1^{\mathrm{IIo}}+4^{\mathrm{I}}$ & $137 \times 118$ & 65 & $21^{\mathrm{IIc}}$ \\
\hline $121 \times 148$ & 53 & $21^{\mathrm{IIc}}$ & $137 \times 138$ & 54 & $21^{\mathrm{IIc}}$ \\
\hline $122 \times 139$ & 24 & $18^{\mathrm{IIc}}+2^{\mathrm{IIo}}+2^{\mathrm{I}}$ & $138 \times 117$ & 32 & $21^{\mathrm{IIc}}$ \\
\hline $122 \times 148$ & 34 & $21^{\mathrm{II} c}$ & $139 \times 128$ & 36 & $20^{\mathrm{IIc}}+1^{\mathrm{IIo}}$ \\
\hline $126 \times 144$ & 29 & $20^{\mathrm{IIc}}+1^{\mathrm{IIo}}$ & $139 \times 146$ & 51 & $17^{\mathrm{IIc}}+2^{\mathrm{IIo}}+4^{\mathrm{I}}$ \\
\hline $126 \times 146$ & 21 & $18^{\mathrm{IIc}}+1^{\mathrm{IIo}}+4^{\mathrm{I}}$ & $140 \times 138$ & 41 & $20^{\mathrm{IIc}}+1^{\mathrm{IIo}}$ \\
\hline $127 \times 117$ & 49 & $20^{\mathrm{IIc}}+1^{\mathrm{IIo}}$ & $140 \times 136$ & 44 & $18^{\mathrm{IIc}}+1^{\mathrm{IIo}}+4^{\mathrm{I}}$ \\
\hline $127 \times 933$ & 26 & $16^{\mathrm{IIc}}+3^{\mathrm{IIo}}+4^{\mathrm{I}}$ & $141 \times 146$ & 28 & $19^{\mathrm{IIc}}+1^{\mathrm{IIo}}+2^{\mathrm{I}}$ \\
\hline $128 \times 138$ & 59 & $20^{\mathrm{IIc}}+1^{\mathrm{IIo}}$ & $141 \times 126$ & 36 & $20^{\mathrm{IIc}}+2^{\mathrm{I}}$ \\
\hline $129 \times 126$ & 14 & $15^{\mathrm{IIc}}+6^{\mathrm{I}}$ & $141 \times 42$ & 34 & $18^{\mathrm{IIc}}+2^{\mathrm{IIo}}+2^{\mathrm{I}}$ \\
\hline $129 \times 143$ & 36 & $18^{\mathrm{IIc}}+2^{\mathrm{IIo}}+2^{\mathrm{I}}$ & $142 \times 126$ & 71 & $19^{\mathrm{IIc}}+2^{\mathrm{IIo}}$ \\
\hline $928 \times 122$ & 44 & $21^{\mathrm{IIc}}$ & $142 \times 136$ & 51 & $19^{\mathrm{IIc}}+1^{\mathrm{IIo}}+2^{\mathrm{I}}$ \\
\hline $933 \times 117$ & 38 & $19^{\mathrm{II} c}+4^{\mathrm{I}}$ & $146 \times 118$ & 55 & $18^{\mathrm{IIc}}+1^{\mathrm{IIo}}+4^{\mathrm{I}}$ \\
\hline $933 \times 121$ & 86 & $21^{\mathrm{IIc}}$ & $148 \times 117$ & 33 & $17^{\mathrm{IIc}}+2^{\mathrm{IIo}}+4^{\mathrm{I}}$ \\
\hline $933 \times 146$ & 23 & $20^{\mathrm{IIc}}+1^{\mathrm{IIo}}$ & $148 \times 128$ & 41 & $17^{\mathrm{IIc}}+2^{\mathrm{IIo}}+4^{\mathrm{I}}$ \\
\hline $134 \times 127$ & 33 & $20^{\mathrm{IIc}}+1^{\mathrm{IIo}}$ & $148 \times 137$ & 31 & $17^{\mathrm{IIc}}+3^{\mathrm{IIo}}+2^{\mathrm{I}}$ \\
\hline $135 \times 117$ & 56 & $20^{\mathrm{IIc}}+1^{\mathrm{IIo}}$ & $148 \times 146$ & 46 & $21^{\mathrm{IIc}}$ \\
\hline
\end{tabular}

Note: * Often trivalents are observed. 
Table 6. Genome structure of the introgressive lines studied

\begin{tabular}{c|c|c|c|c|c}
\hline $\begin{array}{c}\text { Without } \\
\text { translocations }\end{array}$ & \multicolumn{2}{c|}{ One translocation } & \multicolumn{2}{c}{$\begin{array}{c}\text { Two } \\
\text { translocations }\end{array}$} \\
\hline $\begin{array}{c}\text { chromo- } \\
\text { some }\end{array}$ & line & $\begin{array}{c}\text { chromo- } \\
\text { some }\end{array}$ & line & $\begin{array}{c}\text { chromo- } \\
\text { some }\end{array}$ & line \\
\hline $7 \mathrm{~S}^{1}$ & \multicolumn{3}{|c|}{ One chromosome is substituted } \\
\hline
\end{tabular}

Homoeologic belonging of translocations was only to be presumed in most of cases. It suggests that efficiency of the biochemical marker method decreases when not the whole alien chromosome but only its portion as a translocation on the wheat chromosome or as a telocentric chromosome is present in the line genome. This portion may not contain the gene that marks definite chromosome. That is why microsatellite markers attract our attention, as they may be used as markers for different parts of alien chromosomes. It is essential that the use of microsatellite markers requires meticulous prior selection of chromosome specific primers.

Two primer pairs, $X c f d 89$ and $X c f d 106$, for the long (L) and the short (S) arm of chromosome 4D, respectively, were used to screen introgressive lines, cultivar Avrora and genome substitution form Avrorsis (Figs. 1 and 2).

Primer Xcfd89 for the 4DL long produced electrophoretic band (amplicon) when using DNA of variety Avrora and some lines as a matrices. This primer produced no amplicon by using DNA of form Avrosis and certain lines. All the studied lines were identified by us earlier as to presence or absence of the $4 \mathrm{~S}^{1}$ chromosome with the use of some marker genes. These genes were genes $\beta$-Amyl and Acphl which are situated on the long arm of the $4 \mathrm{~S}^{1}$ chromosome (Table 2), and gene $H s-S$ (hairy sheath, Table 1), which was identified by us earlier as a morphological marker of chromosome $4 \mathrm{~S}^{1}$, though the arm localization of the gene was not determined [28]. The lines res 121, res 122, res 126, res 130 , res 141-146, and res 148 are characterized by the presence of amplicon in the spectrum and their leaf sheath have no hairiness. The lines res 115 , res 117 , res 118 , res 127 , res 128 , res 131 , res 134 , res 135 , and res 137-140 have no amplicon in the spectrum and were characterized with the nonhairy leaf sheath (Fig. 1 and Table 1). So, primer Xcfd89 is really specific for wheat chromosome 4D as it was pointed in [16]. This primer can be used for detection of substitution $4 \mathrm{DL} / 4 \mathrm{~S}^{1}$.

The primer $X c f d 106$ produces amplicon when using DNA from all studied strains. However, variety Avrora and form Avrosis differ from each other in intensity of the band. The amplicon of form Avrosis was weaker. Precisely the same difference is observed between amplicons of the lines without chromosome $4 S^{1}$ and with it (Tables 1,2). So, primer Xcfd106 is not specific for chromosome $4 \mathrm{D}$ because it produces amplicon under the absence of chromosome 4D when the 4A and (or) $4 \mathrm{~B}$ chromosomes were used as a matrices. Through the difference in amplicon intensity primer XcfdlO6 can be used for verification of the arm 4DS presence in the line genome. Comparison of results presented in Tables 1, 2 and Figs. 1, 2 allow us to separate the lines demonstrating the biochemical and morphological marker of chromosome $4 \mathrm{~S}^{1}$, in four groups (Table 7).

\section{CONCLUSIONS}

Data presented in the paper concerning the chromosome association in $\mathrm{Ml}$ of PMC in hybrids $\mathrm{F}_{1}$ from crosses between introgressive lines and variety Avrora and with each other and their assessment for some morphological characters and electrophoretic spectra of proteins prove the changes of 1-4 chromosomes in the line genomes in comparison with the variety Avrora genome. The wheat chromosomes are either substituted with chromosome $S^{1}$ from the same homoeologous group or there takes place a rearrangement through translocations, alien-wheat or wheat-wheat. The lines can be separated into six groups with different number of substituted chromosomes of definite homoeologous groups and different number of translocation. Owing to the use the microsatellite markers specific for the 4D chromosome it was estimated that determination of the arm specificity of translocation proved to be possible only for gametocidal chromosome $4 \mathrm{~S}^{1}$.

Table 7. Structure of line genomes for chromosome $4 \mathrm{~S}^{1}$

\begin{tabular}{|c|c|c|c|c|c|c|c|c|c|c|c|c|c|c|c|c|}
\hline \multicolumn{5}{|c|}{ Without $4 S^{1}$} & \multicolumn{7}{|c|}{ With the whole $4 \mathrm{~S}^{1}$} & Only $4 \mathrm{~S}^{1} \mathrm{~L}$ & \multicolumn{4}{|c|}{ Only $4 \mathrm{~S}^{1} \mathrm{~S}$} \\
\hline 121 & 122 & 126 & 130 & $142-145$ & 117 & 118 & $127-129$ & 131 & 134 & 135 & $137-140$ & 115 & 132 & 141 & 146 & 148 \\
\hline
\end{tabular}



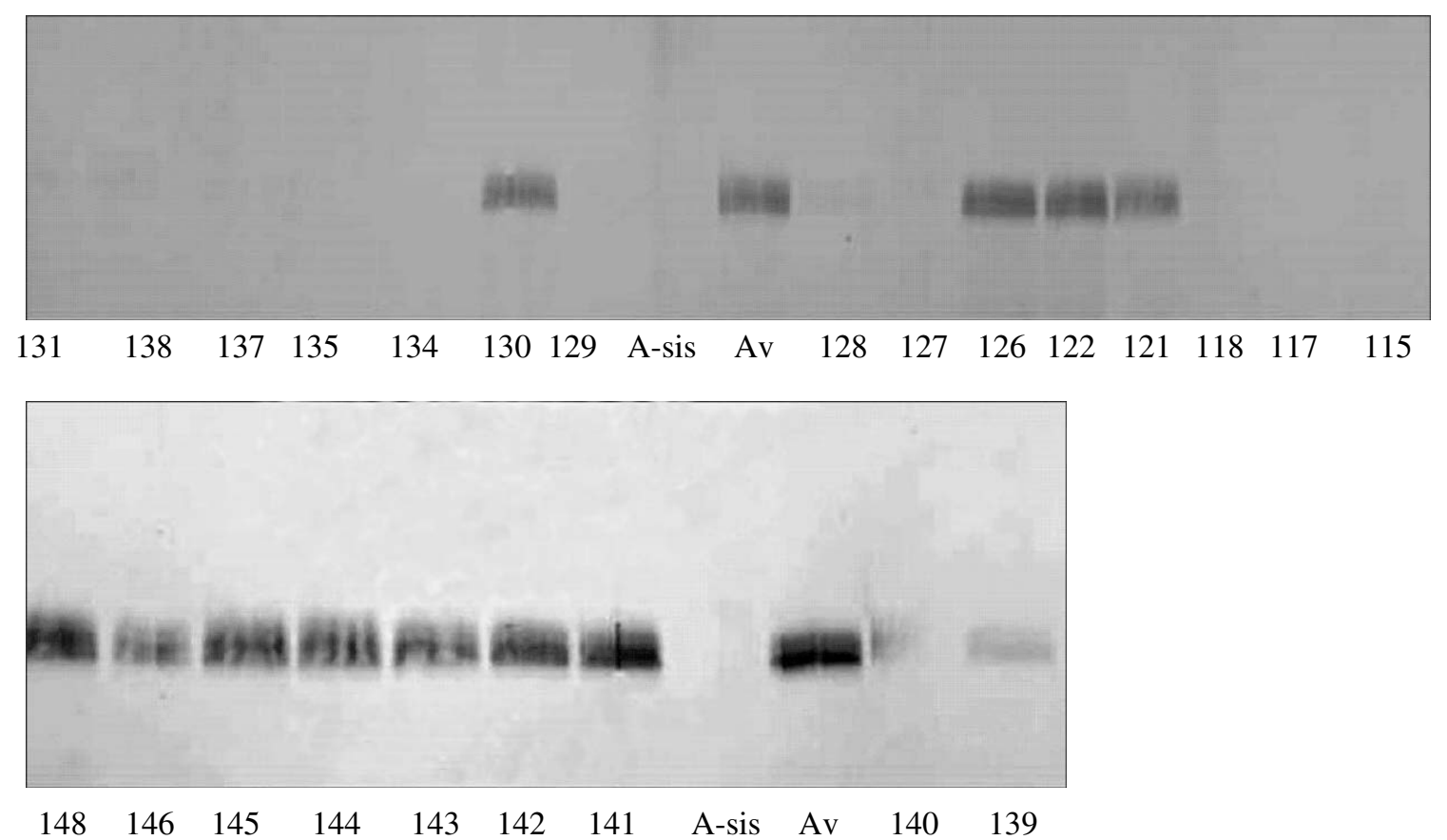

Fig. 1. Electrophoresis pattern of PCR products amplified with Xcfd89 in introgressive lines, Avrora and Avrorsis, where 115-148 are introgressive lines "res", AV - Avrora, AVS - Avrosis.
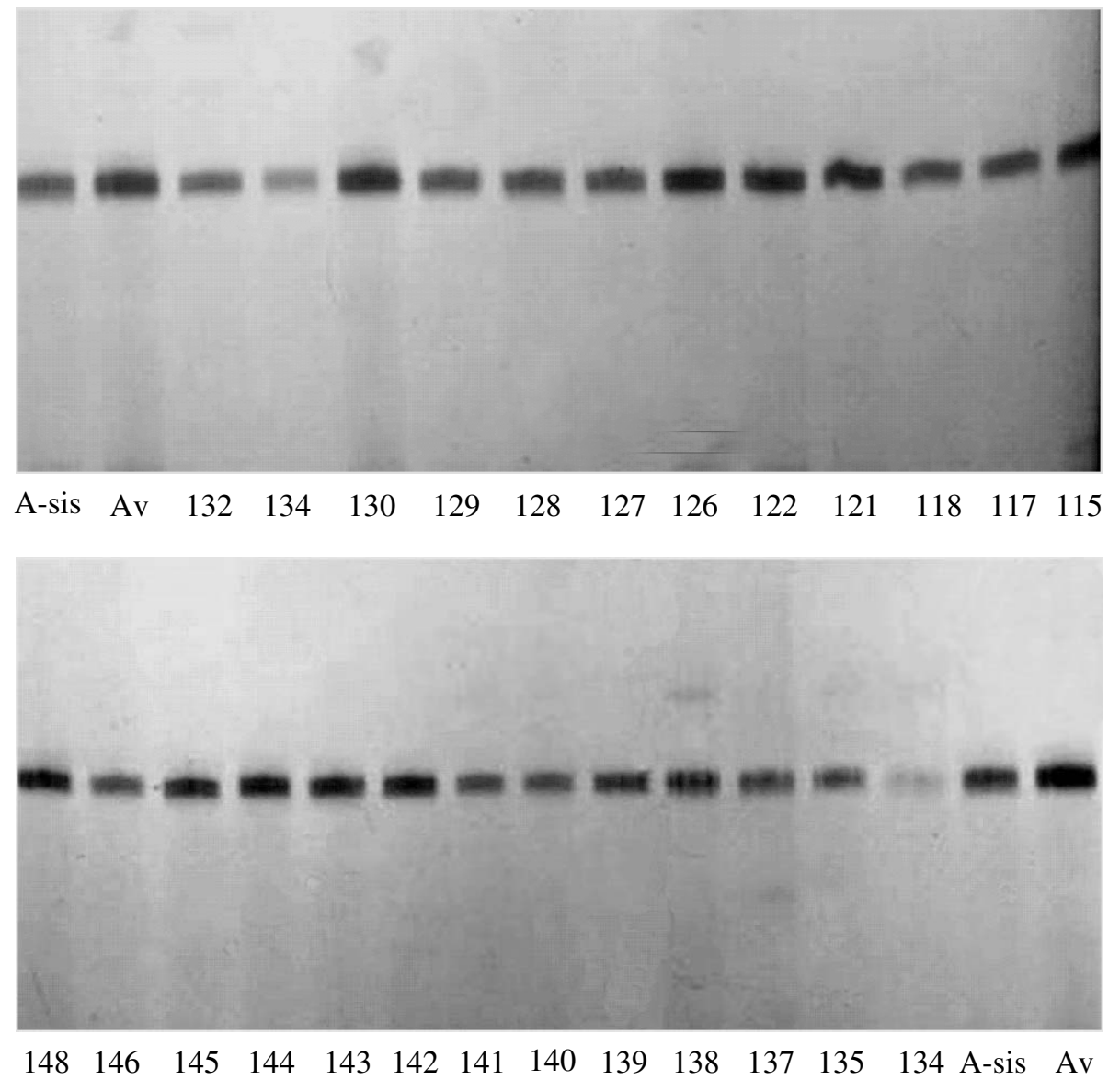

Fig. 2. Electrophoresis pattern of PCR products amplified with Xcfd106 in introgressive lines, Avrora and Avrorsis, 115-148 are introgressive lines "res", AV -Avrora, AVS - Avrosis. 


\section{REFERENCES}

1. Weng, Y., Li, R., Devkota, R.N., and Rudd, J.C., Microsatellite Markers Associated with Two Aegilops tauschii-Derived Greenbug Resistance Loci in Wheat, Theor. Appl. Genet., 2005, vol. 110, pp. 462-469.

2. Simo, M.R., Ayala, F.M., Cordo, C.A., Röder, M.S., and Börner, A., The Use of Wheat/Goatgrass Introgression Lines for the Detection of Gene (S) Determining Resistance to Septoria tritici Blotch (Mycosphaerella graminicola), Euphytica, 2007, vol. 154, pp. 249-254.

3. Perugini, L.D., Murphy, J.P., Marshall, D., and BrownGuedira, G., Pm37, a New Broadly Effective Powdery Mildew Resistance Gene from Triticum timopheevii, Theor. Appl. Genet., 2008., vol. 116, pp. 417-425.

4. Antonio, Blanco A., Gadaleta, A., Cenci, A., Carluccio, A.V., Abdelbacki, A.M.M., and Simeone, R., Molecular Mapping of the Novel Powdery Mildew Resistance Gene Pm36 Introgressed from Triticum turgidum var. Dicoccodes in Durum Wheat, Theor. Appl. Genet., 2008., vol. 117, pp. 135-142.

5. Buerstmayr, H., Ban, T., and Anderson, J.A., QTL Mapping and Marker-Assisted Selection for Fusarium Head Blight Resistance in Wheat: A Review, Plant Breed., 2009, vol. 128, pp. 1-26.

6. Ternovskaya, T.K. and Vdovichenko, Zh.V., Dependence of the Results of a Genetic Analysis of Self-Pollinating Cereal Species on the Specificity of the Mapping Population, Tsitol. Genet., 2003, vol. 37, no. 3, pp. 67-79.

7. Zhirov, E.G. and Ternovskaya, T.K., Transfer of Aegilops sharonensis Eig. Chromosome to the Wheat Triticum aestivum L., Which Makes It Resistant to Powdery Mildew, Genetika, 1993, vol. 29, no. 4, pp. 639-645.

8. Zhirov, E.G. and Ternovskaya, T.K., Genomic Engineering in Wheat, Vestn. S.-Khoz. Nauk, 1984, no. 10, pp. 58-66.

9. Antonyuk, M.Z., Ternovskaya, T.K., and Sozinov, A.A., Identification of Blocks of Electrophoretic Components of Storage Proteins Encoded by Genes of Three Aegilops Species, Fiziol. Biokhim. Kul't. Rast., 1994, vol. 26, no. 5, pp. 474-481.

10. Antonyuk, M.Z. and Ternovskaya, T.K., $\beta$ and $\alpha$ Amylase Isozymes for Identification of Genetic Material of Three Aegilops Species, Inserted into the Common Wheat Genome, Tsitol. Genet., 1995, vol. 29, no. 2, pp. 3-8.

11. Antonyuk, M.Z., Ternovskaya, T.K., and Zlatskaya, A.V., Identification of Genes of Grain Peroxidase in Three Aegilops Species, Agroekologiya. Zb. Nauk. Pr. Inst. Agroekol. Biotekhnol. (Agroecology: Collected Papers of the Institute of Agroecology and Biotechnology), Kiev: Agrar. Nauka, 1996, pp. 239-245.

12. Antonyuk, M.Z., Zlatskaya, A.V., and Martynenko, V.S., Genes Encoding Grain and Leaf Esterases as Biochemical Markers of Chromosomes of Three Aegilops Species and Migusheva Wheat, Agroekologiya ta Biotekhnologiya: Zb. Nauk. Pr. Inst. Agroekol. Biotekhnol. (Agroecology and Biotechnology: Collected Papers of the Institute of Agroecology and Biotechnology), Kiev: Agrar. Nauka, Kiev: Agrar. Nauka, 1998, issue 2, pp. 169-179.
13. Vdovichenko, Zh.V., Antonyuk, M.Z., Zlatskaya, A.V., and Ternovskaya, T.K., Acid Grain Phosphatase as a Genetic Marker of Chromosomes of the Fourth Homeological Group in Aegilops and Wheat, Tsitol. Genet., 1999, vol. 33, no. 5, pp. 42-46.

14. Heslop-Harrison, J.S., CTAB Technique for DNA Extraction from Leaves Samples, PHH4@le.ac.uk.

15. Sourdille, P., Singh, S., and Cadalen, T., MicrosatelliteBased Deletion Bin System for the Establishment of Genetic-Physical Map Relationships in Wheat Triticum aestivum, L., Funct. Integr. Genom., 2004, vol. 4, pp. 12-25.

16. Röader M.S., Korzun, V., Wendehake, K., Plaschke, J., Tixier, M.H., Leroy, P., and Ganal, W., A Microsatellite Map of Wheat, Genetics, 1998, vol. 149, pp. 2007-2023.

17. Glantz, S.A., Primer of Biostatistics, McGraw-Hill, 2002, p. 468.

18. McIntosh R.A., Hart G.E., Devos K.M., Gale M.D., Rogers W.J. Catalogue of Gene Symbols for Wheat, in Proc. 9th Intern. Wheat Genet. Symp. Saskatoon (Saskatchewan, Canada, August 2-7, 1998), Slinkard, A.E., Ed., Saskatoon: Univ. Extention Press, 1998, vol. 5, p. 235.

19. Miller, T.E. and Reader, S.M., A Guide to the Homoeology of Chromosomes within the Triticeae, Theor. Appl. Genet., 1987, vol. 74., no. 2, pp. 214-217.

20. Antonyuk, M.Z. and Ternovskaya, T.K., Plant Morphological Traits as Markers of Homeological Groups of Triticinae Chromosomes, Tsitol. Genet., 1997, vol. 31, no. 4, pp. 95-101.

21. Kerber, E.R. and Rowland, G.G., Origin of the Free Threshing Character in Hexaploid Wheat, Can. J. Genet. Cytol., 1974, vol. 16, no. 1, pp. 145-154.

22. Ternovskaya, T.K. and Zhirov, E.G., The D Genome of Common Wheat. Genetic Control of the Traits of Glume Softness and Base Basin, Tsitol. Genet., 1993, vol. 27, no. 5, pp. 78-83.

23. Mettin, D., Bluthner, W.D., and Schlegel, G., Additional Evidence on Spontaneous 1B/1R Wheat-Rye Substitutions and Translocations, in Proc. 4th Int. Wheat. Genet. Symp., Columbia, Mo.), 1973, pp. 179-184.

24. Zhirov, E.G., Bessarab, K.S., and Gubanova, M.A., Genetic Study of Partial Desynapsis of Common Wheat, Genetika, 1973, vol. 9., no. 1, pp. 18-29.

25. Zhirov, E.G. and Ternovskaya, T.K., Analysis of Chromosome Synapsis in Wheat Hybrids in Relation to the Origin of Wheat Genomes: Triploid Hybrids, Genetika, 1993, vol. 29, no. 1, pp. 135-143.

26. Riley, R., Unrau, J., and Chapman, V., Evidence on the Origin of the B Genome of Wheat, J. Hered., 1958, vol. 49, pp. 91-98.

27. Zhirov, E.G. and Ternovskaya, T.K., Analysis of Chromosome Synapsis in Wheat Hybrids in Relation to the Origin of Wheat Genomes: Diploid Hybrids, Genetika, 1993, vol. 29, no. 1, pp. 125-134.

28. Vdovichenko, Zh.V., Zlatskaya, A.V., and Ternovskaya, T.K., A New Morphological Chromosome Marker in the Fourth Homeological Group of Triticinae, Tsitol. Genet., 2001, vol. 35, no. 1, pp. 28-33. 